\title{
Are Primary Health Care Workers Aware of Cervical Cancer Risk?
}

\author{
Huseyin Can ${ }^{1,2 *}$, Ozgur Erdem ${ }^{3}$, Coskun Oztekin ${ }^{4}$, Sercan Bulut Celik ${ }^{4}$, Mete \\ Onde $^{5}$, Tahsin Celepkolu ${ }^{6}$, Kurtulus Ongel ${ }^{1,7}$
}

\begin{abstract}
Background: We here examined the awareness of female health employees (doctors, nurses, midwives) working in primary health care service about cervical cancer and its risk factors. Additionally attitude and behavior for gynecologic examination and pap smear screening wwere researched. Materials and Methods: This cross-sectional, descriptive study con cerned female health employees working at primary health care services in two southern cities of Turkey, over a four month period in 2013. Participants were recently or previously sexually active research was explained and verbal informed consent was obtained face to face. The questionnaire consisted of two parts; socio-demographic characteristics and level of knowledge about cervical cancer and its risk factors. Results: The average age of the participants (midwives $43.7 \%, n=143$; nurses $40.4 \%$, $n=132$; doctors $6.4 \%, n=21$; emergency medical technicians and others, $9.5 \%, n=31$; total, $n=327$ ) was $30.9 \pm 6.41$ years. 64.2\% ( $(n=210)$ were working in Diyarbakir and 35.8\% ( $n=117)$ in Batman. A large proportion reported low knowledge and inadequate screening practice Conclusions: Health employees should be better informed about the importance of screening for cancers, given their preventive roles for the general population.
\end{abstract}

Keywords: Cervical cancer - primary healthcare workers - Pap smear - knowledge

Asian Pac J Cancer Prev, 15 (16), 6669-6671

\section{Introduction}

Worldwide, cervical cancer is one of the leading causes of morbidity and mortality among gynaecological cancers, and is second to breast cancer as the commonest female cancer (Jemal et al., 2008a,b). Most important cause of the cervical cancer is "Human Papilloma Virus" (HPV) (Saslow et al., 2007). Screening for cervical cancer has been one of the few tests which have been shown to be able to directly reduce mortality and morbidity (Huh 2010). Early diagnosis and treatment is crucial for decreasing the mortality rate in the cervical cancer (Coskun et al., 2013). There are various methods to detect premalignant lesions such as conventional Pap smear (Oranratanaphan et al., 2010). Pap smear testing is an effective method of detecting, preventing and delaying the progress of cervical cancer (Bebis et al., 2012; Shieh et al., 2012 ; Sogukpinar et al., 2013; Karadag et al., 2014). Poor knowledge about cervical cancer, and lack of awareness of available screening methods have been identified as the most important factors hindering the use of available cervical cancer screening services (Nwankwo et al.2011). In a selected population, it is the women healthcare workers who are expected to have the most adequate and updated information regarding cervical cancer. However, studies have shown that this suggestion may not be true, since most of the women healthcare workers do not have adequate information regarding the risk factors of cervical cancer and, even if they have, they do not routinely visit gynecologists and have Pap smear. (Tarwireyi et al., 2003; Can et al., 2010; Coskun et al., 2013). Primary healthcare workers are the main drivers of the population-oriented health education programs. They have to be equipped with accurate and adequate information to be able to serve as trainer and consultant in the preventive healthcare services not only against cervical cancer but all cancer types (Coskun et al., 2013).

This study aims to determine the knowledge level of the female primary healthcare workers about cervical cancer, a commonly seen and preventable cancer, and its risk factors. It also aims to reveal their attitude and behaviors towards having gynecological examination and Pap smear, both of which have a vital importance for the prevention and early diagnosis of the cervical cancer.

\section{Materials and Methods}

This descriptive, cross-sectional study was conducted

${ }^{I}$ Department of Family Medicine, Faculty of Medicine, ${ }^{2}$ Family Medicine Clinic, Katip Celebi University, Atatürk Education and Research Hospital, Izmir, ${ }^{3}$ Kayapınar Family Health Center Number 9, Diyarbakır, ${ }^{4}$ Family Health Center Number 11 , ${ }^{5}$ Community Health Center Number 1, Batman, ${ }^{6}$ Department of Family Medicine, Faculty of Medicine, Dicle University, Diyarbakir, ${ }^{7}$ Family Medicine Clinic, Tepecik Education and Research Hospital, Izmir, Turkey*For correspondence: drhuseyincan@hotmail.com 
in 327 female primary healthcare workers (physician, nurse, midwifes, other assistant healthcare professionals) in the province of Batman and Diyarbakir, two Southern city of Turkey. We aimed to enlist all employees from the primary women's health services located in Batman and Diyarbakır city centers. Of all these, approximately $60 \%$ $(n=327)$ agreed to participate.

The study was approved by local health authority of Batman and Diyarbakir and also Ethics Committee of Tepecik Training and Research Hospital. 327 women healthcare workers who were or have been sexually active have participated in the study. The questionnaires prepared by the investigators were done in a personal interview. In the questionnaire, the first part included the questions about socio-demographic characteristics of the healthcare workers and the second part included the questions about their knowledge level about cervical cancer and its risk factors and their attitude and habitudes about gynecological examination and Pap smear test. We questioned the behaviors of the female primary healthcare workers in early diagnosis and screening. However, we did not question their reasons for not having early diagnostic methods, which consists one of the limitations of our study.

In the study, descriptive analyses used mean \pm standard deviation (minimum-maximum) and percentage (number), whereas intergroup comparisons were done using chisquare test. The $\mathrm{p}<0.05$ was considered to be significant.

\section{Results}

The average age of the participants (midwife $43.7 \%$, $\mathrm{n}=143$; nurse $40.4 \%, \mathrm{n}=132$; doctor $6.4 \%, \mathrm{n}=21$; emergency medical technician and others, 9.5\%, $\mathrm{n}=31$; total, $\mathrm{n}=327)$ was $30.89 \pm 6.41$ years. $64.2 \%(\mathrm{n}=210)$ were working in Diyarbakir and $35.8 \%(n=117)$ in Batman. $56.9 \%$ of the participants $(n=186)$ has bachelor degree, $41.0 \%(n=134)$ has high school degree, $2.1 \%(n=7)$ secondary school degree. $64.5 \%$ of the participants $(\mathrm{n}=211)$ were married, $33.7 \%(\mathrm{n}=110)$ single and $1.8 \%$ $(n=6)$ divorced. The average age of menarche was $13.60 \pm 1.38$ years, and $1.2 \%$ of the participants $(n=4)$ was in menopause, but none was on hormone replacement therapy. The average age of menopause was $49.67 \pm 2.51$ years, and $86.7 \%(n=242)$ of those giving information regarding their menstruation periods reported regular menstruation. The average number of conceptions for 192 individuals having a gestation history was $2.22 \pm 1.31$ and, $91.1 \%(n=175)$ had at least one delivery, $23.9 \%(n=46)$ has at least one miscarriage, $11.5 \%(n=22)$ has at least one abortion and $4.7 \%(n=9)$ haf at least one stillbirth. The answers given by the participants in response to the questions on pap smear testing is presented in Table 1.

$25.9 \%(n=47)$ of 181 persons who claimed to know when one should start having pap smear tests answered correctly. $82.2 \%(n=226)$ of 275 persons who claimed to know which diseases pap smear testing is used to diagnose answered correctly. $70.6 \%(n=207)$ of 293 persons who claimed to know in which frequency one should have pap smear testing answered correctly. The distribution of answers based on location is given in Table 2 .

92.2\% $(\mathrm{n}=295)$ of the participants knew having more
Table 1. The Answers Given by the Participants in Response to the Questions on Pap smear Testing

\begin{tabular}{llc}
\hline Question & & $\%$ (No.) \\
\hline Are you having regular & Yes & $23.5(76)$ \\
gynaecological examination? & No & $76.5(248)$ \\
What is the frequency of your & Every 6 months & $5.5(18)$ \\
gynaecological examinations & Annually & $11.6(38)$ \\
& Biennially & $2.1(7)$ \\
& Triennially & $1.5(5)$ \\
& Less frequent & $2.4(8)$ \\
Have you ever heard of & Yes & $75.9(242)$ \\
pap smear testing before? & No & $24.1(77)$ \\
Have you ever had a & Yes & $33.0(88)$ \\
pap smear test before? & No & $67.0(179)$ \\
What is the number of & 1 & $17.6(47)$ \\
pap smear tests you had? & 2 & $10.2(27)$ \\
& 3 & $2.6(7)$ \\
Do you know when one should & I know & $2.6(7)$ \\
start having pap smear tests? & I don't know & $59.5(181)$ \\
\hline
\end{tabular}

Table 2. Distribution of Answers Based on Location

\begin{tabular}{|c|c|c|}
\hline \multicolumn{2}{|c|}{ Location } & \multirow{3}{*}{$\mathrm{p}$} \\
\hline Batman & Diyarbakır & \\
\hline$\% *$ & $\%^{*}$ & \\
\hline
\end{tabular}

Are you having regular gynaecological examination?

$\begin{array}{lllrrr}\text { Yes } & 34 & 29.1 & 42 & 20.3 & 0.074 \\ \text { No } & 83 & 70.9 & 165 & 79.7 & \end{array}$

Have you ever heard of pap smear testing before?

$\begin{array}{lrrrrr}\text { Yes } & 94 & 80.3 & 148 & 73.3 & 0.155 \\ \text { No } & 23 & 19.7 & 54 & 26.7 & \end{array}$

Have you ever had a pap smear test before?

$\begin{array}{llllll}\text { Yes } & 34 & 29.1 & 54 & 36.0 & 0.231 \\ \text { No } & 83 & 70.9 & 96 & 64.0 & \end{array}$

Do you know which diseases pap smear testing is used to diagnose? $\begin{array}{llllll}\text { Right } & 95 & 89.6 & 131 & 77.5 & 0.011\end{array}$

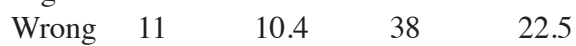

Do you know when one should start having pap smear tests? $\begin{array}{llllll}\text { Yes } & 68 & 58.1 & 113 & 60.4 & 0.690\end{array}$

$\begin{array}{lllll}\text { No } & 49 & 41.9 & 74 & 39.6\end{array}$

Is the answer given to the question regarding when to start having pap smear tests?
$\begin{array}{lllll}\text { Yes } & 30 & 44.1 & 17 & 17.3 \\ \text { No } & 38 & 55.9 & 81 & 82.7\end{array}$
$<0.001$

Is the answer given to the question regarding how frequent one should have pap smear tests?

\begin{tabular}{lrrrrr} 
Yes & 84 & 75.0 & 123 & 68.0 & 0.198 \\
No & 28 & 25.0 & 58 & 32.0 & \\
\hline
\end{tabular}

*Column percentage

than one partner increases the cervical cancer risk. This was $96.5 \%$ for Batman, and $89.8 \%$ for Diyarbakir ( $\mathrm{p}=0.030)$. $84.9 \%(n=270)$ of the participants knew that HPV that is transmitted during intercourse may cause cervical cancer, and there was no significant difference between cities $(\mathrm{p}=0.907) .65 .1 \%(\mathrm{n}=213)$ of the participants knew that the early sexual intercourse increases cervical cancer risk, the rate was $75.2 \%$ for Batman group and $67.4 \%$ for Diyarbakir group $(\mathrm{p}=0.027) .86 .4 \%$ of the participants $(\mathrm{n}=279)(\mathrm{p}=0.301)$ knew that smoking increases the cervical cancer risk and $78.8 \%(n=252)(p=0.373)$ knew one could protect herself from cervical cancer via injection and other measures. 


\section{Discussion}

Cervical cancer is the second most common cancer in women worldwide with nearly 500,000 new cases each year (Hoque and Hoque, 2009; Senol et al., 2012; Ersin and Bahar, 2013). Pap smear testing is an effective method for detecting, preventing and delaying the progress of cervical cancer (Bebis et al., 2012; Ersin and Bahar, 2013; Karadag et al., 2014). The female health care worker plays important roles as a health educator and a promoter. Therefore, unsatisfactory knowledge and low compliance with screening recommendations may lead to negative impact on community in undergoing a Pap smear (Nilaweera et al., 2012).

In this study, in accordance with other studies; we found that the rate of having pap smear test is higher among the healthcare personnel informed on pap smear testing, having regular gynaecological, and informed on cervical cancer, its risks, HPV and injection (Wellensiek et al., 2002; Coskun S et al., 2013). But when all participants are taken in view, we found that the rate of having pap smear test and having regular gyneacological examinations are low (33.0\% and $23.5 \%$, relatively), although knowledge levels of the participants are high. Many other studies found such low levels in terms of having regular gyneacological examinations and pap smear testing among healthcare workers (Nilaweera et al., 2012; Coskun et al., 2013; Karadag et al., 2014). Because primary healthcare personnel is the ones that meets patients first, they should be informed of pap smear testing and the risk factors of cervical cancer and taken to in-service trainings if necessary. Although we compared two cities located in the east of Turkey, similar results have been found for many other cities. It can be concluded that similar results have been obtained because these cities are in the same region and sharing the same culture.

Continuous training of primary care workers, extending the screening programs, regulating health policies and systems, informing people and changing their behaviors and attitudes may positively effect the public health. Because of their role in the preventive health services, We should determine the knowledge levels of healthcare personnel through epidemiologic studies and take actions.

As a result of the study, we think that the importance of the issue by organizing in-service trainings for female primary healthcare workers and the importance of having diagnostic tests should be re-highlighted. The studies are warranted to describe the psychological factors that cause them not having this test. It is hoped that the findings might be useful at policy making levels related to this important public health issue.

\section{Acknowledgements}

We are grateful to all the female health care workers who participated in the study. about cervical cancer and papanicolaou testing on the behavior, knowledge, and beliefs of Turkish women. Int $J$ Gynecol Cancer, 22, 1407-12.

Can H, Kılıç Öztürk Y, Güçlü YA, et al (2010). Awareness of cervical cancer among female health carers. J Tepecik Teaching Hospital, 20, 77-84.

Coskun S, Can H, Turan S (2013). Knowledge about cervical cancer risk factors and Pap smear testing behavior among female primary health care workers: a study from south of Turkey. Asian Pac J Cancer Prev, 14, 6389-92.

Ersin F, Bahar Z (2013). Barriers and facilitating factors perceived in Turkish women'sbehaviors towards early cervical cancer detection: A qualitative approach. Asian Pac J Cancer Prev, 14, 4977-82.

Hoque E, Hoque M (2009). Knowledge of and attitude towards cervical cancer amongfemale university students in South Africa. South Afr J Epidemiol Infect, 24, 21-4.

Jemal A, Thun MJ, Ries LA, et al (2008a). Annual report to the nation on the status of cancer, 1975-2005, featuring trends in lung cancer, tobacco use, and tobacco control. J National Cancer Instit, 100, 1672-94.

Jemal A, Siegel R, Ward E, et al (2008b). Cancer statistics, 2008. CA: A Cancer J Clin, 58, 71-96.

Huh W.K. (2010) The changing face of cervical cancer screening in the United States. J National Comprehensive Cancer Network, 8, 1329-30.

Karadag G, Gungormus Z, Surucu R, et al (2014). Awareness and practices regarding breast and cervical cancer among Turkish Women in Gaziantep. Asian Pac J Cancer Prev, 15, 1093-8.

Nilaweera RIW, Perera S, Paranagama N, et al (2012). Knowledge and practices on breast and cervical cancer screening methods among female health care workers: a sri lankan experience. Asian Pac J Cancer Prev, 13, 1193-6.

Nwankwo KC, Aniebue UU, Aguwa EN, et al. (2011). Knowledge attitudes and practices of cervical cancer screening among urban and rural Nigerian women: a call for education and mass screening. Eur J Cancer Care, 20, 362-7.

Oranratanaphan S, Amatyakul P, Iramaneerat K, et al (2010). Knowledge, attitudes and practices about the Pap smear among medical workers in Naresuan University Hospital, Thailand. Asian Pac J Cancer Prev, 11, 1727-30.

Saslow D, Castle PE, Cox JT, et al (2007). American Cancer Society Guideline for human Papillomavirus (HPV) vaccine use to prevent cervical cancer and its precursors. $C A$ Cancer J Clin, 57, 7-28.

Senol V, Balci E, Cetinkaya F, Balci F (2012). Women's knowledge and behavior oncervical cancer, in Kayseri, Turkey. Turkiye Klinikleri J Med Sci, 32, 694-701.

Shieh SH, Chen HC, Tsai WC, et al (2012). Impact of breast cancerpatients' awareness on attendance at screening. Int Nurs Rev, 59, 353-61.

Sogukpinar N, Karaca Saydam B, Ozturk Can H, et al (2013). Assessment of cervical cancer risk in women between 15 and 49 years of age: Case of Izmir. Asian Pac J Cancer Prev, 14, 2119-25.

Tarwireyi F, Chirenje ZM, Rusakaniko R (2003). Cancer of the cervix: knowledge, beliefs and screening behaviours of health workers in mudzi district in mashonaland east province, Zimbabwe. Cent Afr J Med, 49, 83-6.

Wellensiek N, Moodley M, Moodley J, et al (2002). Knowledge of cervical cancer screening and use of cervical screening facilities among women from various socioeconomic backgrounds in Durban, Kwazulu Natal, South Africa. Int J Gynecol Cancer, 12, 376-82.

\section{References}

